\title{
Adenosine-induced stress myocardial perfusion MRI using SW-CG-HYPR with whole left ventricular coverage: comparison of results with X-ray angiography in patients with suspected CAD
}

Heng $\mathrm{Ma}^{1 *}$, Lan $\mathrm{Ge}^{2}$, Jing $\mathrm{An}^{3}$, Lixin $\mathrm{Jin}^{4}$, Renate Jerecic ${ }^{4}$, Kuncheng $\mathrm{Li}^{1}$, Debiao $\mathrm{Li}^{2}$

From 2011 SCMR/Euro CMR Joint Scientific Sessions

Nice, France. 3-6 February 2011

\section{Introduction}

Myocardial perfusion MRI with sliding-window conjugate-gradient HYPR (SW-CG-HYPR) allows increased spatial coverage (whole left ventricular coverage), resolution, signal-to-noise ratio and reduced motion artifacts. The accuracy of this technique for detecting coronary artery disease (CAD) has not been determined in a large number of patients.

\section{Purpose}

The purpose of this study was to prospectively evaluate the diagnostic performance of adenosine-induced stress myocardial perfusion MRI with SW-CG-HYPR in patients with suspected CAD.

\section{Methods}

Forty consecutive patients (23 men and 17 women; mean age, $56 \pm 15$ years) with suspected CAD who were scheduled for coronary angiography underwent myocardial adenosine stress perfusion MRI with SW-CG-HYPR at 3.0T. Perfusion defects were interpreted visually by 2 blinded observers and were correlated to $\mathrm{x}$-ray angiographic stenoses $\geq 50 \%$.

\section{Results}

The prevalence of CAD was 55\%. In the per-patient analysis, the sensitivity, specificity and accuracy of

${ }^{1}$ Xuanwu Hospital, Capital Medical University, Beijing, China

Full list of author information is available at the end of the article
SW-CG-HYPR myocardial perfusion imaging were 95\%, $83 \%$ and $90 \%$, respectively. In the per-vessel analysis, these values were $98 \%, 89 \%$ and $93 \%$, respectively. Figure 1 illustrates the detection of significant CAD by SW-CG-HYPR myocardial perfusion imaging with correlation to $\mathrm{X}$-ray coronary angiography.

\section{Conclusions}

Adenosine-Induced stress myocardial perfusion MRI using SW-CG-HYPR allows whole left ventricular coverage and has high diagnostic accuracy in patients with suspected CAD.

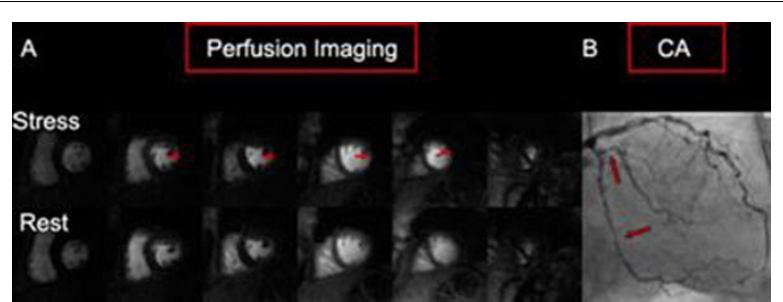

Figure 1 A 56-year-old man with no prior cardiac history who presented with chest pain. (A) Myocardial perfusion MRI with sliding-window conjugate-gradient HYPR (SW-CG-HYPR) detects perfusion defects in the basal, mid, and apical lateral segments, corresponding to significant stenoses in the left circumflex coronary artery (LCX). (B) Coronary angiography (CA) confirms significant stenoses in the LCX. 


\section{Author details}

${ }^{1} X u a n w u$ Hospital, Capital Medical University, Beijing, China. ${ }^{2}$ Department of Radiology, Northwestern University, Chicago, IL, USA. ${ }^{3}$ Siemens Healthcare, MR Collaboration NE Asia, Siemens Mindit Magnetic Resonance, Shenzhen, China. ${ }^{4}$ Siemens Healthcare, MR Collaboration NE Asia, Siemens Limited

China, Shanghai, China.

Published: 2 February 2011

doi:10.1186/1532-429X-13-S1-P78

Cite this article as: Ma et al:: Adenosine-induced stress myocardial perfusion MRI using SW-CG-HYPR with whole left ventricular coverage: comparison of results with X-ray angiography in patients with suspected CAD. Journal of Cardiovascular Magnetic Resonance 201113 (Suppl 1):P78.

Submit your next manuscript to BioMed Central and take full advantage of:

- Convenient online submission

- Thorough peer review

- No space constraints or color figure charges

- Immediate publication on acceptance

- Inclusion in PubMed, CAS, Scopus and Google Scholar

- Research which is freely available for redistribution

Submit your manuscript at www.biomedcentral.com/submit 